\title{
Children’s Who are Blind Voices Concerning Science
}

\author{
Yiannoula Andre ou ${ }^{1, *}$, Spyridon-Georgios Soulis ${ }^{2}$, Panagiota Andreou ${ }^{1}$, Pinio Xris todoulou ${ }^{2}$ \\ ${ }^{1}$ Primary education, Ministry of Education, Larnaca, Cyprus \\ ${ }^{2}$ Primary education, University of Ioannina, Greece
}

\begin{abstract}
The purpose of the present paper is to elicit views about basic aspects of children's who are blind perceptions and knowledge of science in the view of the fact that science education (visual displays, graphical materials, experiments and so on) might pose a number of significant challenges in conditions without vision. Teaching blind child ren about natural phenomenon requires a different approach and methodology to the one used for sighted children. Such methods have to take into account that, by definition, sighted and visually impaired children experience physical phenomenon in different ways[1]. As a result specific equip ment such as assistive technology, accessible instruments, tactile graphics materials and strategies that could help children meets those challenges in order to acquire equivalent proficiencies as their sighted peers are needed[2].Taking into consideration the above mention challenges children who are blind were interviewed to find out the way they viewed science. Examp les of their understanding of science issues are presented, as identified from the interviews. The imp lications for teaching science education are discussed.
\end{abstract}

Keywords Children Who Are Blind, Science Education, Scientists

\section{Introduction}

Findings from a range of studies have found that the way students observe or interpret the world around them is affected by their pre-existing ideas ([3],[4],[5], and[6]). In addition these ideas, which are constructing from the interactive relationship between children and their natural and social environment, influence their understanding of concepts that are going to be taught at school. Children most of the time observe, explore, discover, and ask questions about the world in which they live, so it's logical to create their own simplify explanations about how and why things behave as they do. These explanations are very often deficient or incorrect. That is why school and teachers have enormous responsibility to design learning opportunities and experiences in order to relate the scientific knowledge to children's experience and moreover to change children's deficient interpretations ([1]).

"If science teaching is to influence how children think about the world as they have experienced it then what is learnt in school science must be about, or relatable to, that earlier experience" ([7])

Practical work in science followed by discussion and interpretation can clarify and strengthen the knowledge of the realities around us. Es pecially for children whose experience of their environment has been limited and whose

* Corresponding author:

andreouyiannoula@yahoo.com (Dr. Yiannoula Andreou)

Published online at http://journal.sapub.org/edu

Copyright (C) 2012 Scientific \& Academic Publishing. All Rights Reserved understanding of it confused by visual impairment, these practical opportunities are of even greater importance.

There is a growing literature on mainstream school children's education about science ([7],[3],[4], and[5]) but there have been only a few systematic studies of children who are visually impaired and the teaching of science ([1],[2]). As a starting point to address this issue and to elicit views about basic aspects of children's who are blind perceptions and knowledge of science we carried out pilot qualitative interviews with four boys aged 10 to 13 years attending two schools for the children who are blind - two boys from a primary school and two boys from a secondary school.

\section{Method and Procedure}

The main criteria for selecting children to participate in the present study were that the children should have a visual acuity level of total blindness or light perception only; should be in the 10 to 13 years age range and have no additional disabilities ([8],[9]). This age range was used by another study[10] which examined science teaching of mainstream school children. The same age range was used by reference[1]. These researchers[1] investigated how blind and sighted children understand the basic physics that they experience in their everyday lives.

The boys in the present study had been blind since birth: Bill (aged 10), Bob (aged 11), Ben (aged 12) and Brian (aged 13). Ben had no light perception at all while the other boys had light perception. All four of them used Braille to read and they had science lessons two to three times a week. 
Table 1. Background information

\begin{tabular}{|c|c|c|c|c|}
\hline Students & $\begin{array}{c}\text { Age at first } \\
\text { interview }\end{array}$ & Sex & $\begin{array}{c}\text { Age of } \\
\text { onset of } \\
\text { blindness }\end{array}$ & $\begin{array}{c}\text { Visual } \\
\text { perception }\end{array}$ \\
\hline Bill & 10 & male & Birth & $\begin{array}{c}\text { Light } \\
\text { perception }\end{array}$ \\
\hline Bob & 11 & male & Birth & $\begin{array}{c}\text { Light } \\
\text { perception. } \\
\text { Recognizes } \\
\text { some well } \\
\text { saturated } \\
\text { colors }\end{array}$ \\
\hline Ben & 12 & male & Birth & $\begin{array}{c}\text { No vision at } \\
\text { all }\end{array}$ \\
\hline Brian & 13 & male & Birth & $\begin{array}{c}\text { Light } \\
\text { perception }\end{array}$ \\
\hline
\end{tabular}

The schools were visited by the first author of this paper and the aims of the study were discussed with the relevant professionals and the children themselves. Schools obtained parental permission for the children that were identified as meeting the above criteria to be involved in the research. It was explained to those concerned that the children were to be visited by the researcher who would spend time getting to know them and observing them in their science lesson activities for four months ([8]).

In the present study we used in-depth interviews as the main tool for the data collection. We also used observation data. Although it should be noted that observations were primarily used as a means of deepening understanding of the setting rather than as a means of data collection ([8],[9]). However in practice they did provide interesting additional evidence, especially in terms of reinforcing and checking initial understanding gained from interviews about how children were thinking and acting when engaged in science lessons.

As a pilot study, it was designed to elic it views about basic aspects of visually impaired children's perceptions and knowledge of science as the potential foundation for the PhD of the first author of the present paper. In the event, the PhD took a different direction but we felt that the data as preliminary as it is would be of interest to those concerned with science, pedagogy and its application to vision impaired children. We hope that the reporting here of our findings might spark the interests of those who will want to take the research further.

\section{Findings}

Research ([6],[7], and[10]) has provided a us eful overview about traditional notions of teaching mainstream children about science and the critiques of these notions. Is been discussed the view that one of the goals of teaching young children about science is to enable them to become scientifically 'literate' as a means of equipping them to be able to take part in debates about science. That this end might have been achieved with the boys in our study is suggested by the way that they defined science in terms of specific topics such as electricity, magnetism, plants and the human body while the eldest child also defined it in terms of the main disciplines of physics, chemistry and biology. In other words, their ability to differentiate conceptually at a young age between the main strands of science suggested that they have basic science literacy.

Reference[6], also described the idea that to become science literate, children need to be given structured instruction in basic scientific ideas but for this to be complimented with experience in the use of scientific methods through experiment. And to avoid any misunderstanding about scientific concepts, they should be encouraged to express their opinion and to test them through experimentation. However, these approaches have been questioned. In particular, the nature of scientific activ ity is so diverse and complex that it cannot possibly be replicated in the classroom. However, as observed,[6], this has not changed the core aspiration in teaching that science literacy is seen as a 'good thing' and a desirable goal in its own right.

\subsection{Children Ascribed Social Value to Science}

A study,[6], of mainstream children found that they did not see any relationship about the science they learnt in the classroom and its relevance to their everyday lives. This is very different to the children in our study who ascribed social value to science either in terms of it being a means of developing knowledge as an end in itself or of use to humans.

"...it is really good...information ... you can learn about the world around you..." (Bob aged11)

..."you need to learn about your body and about the different foods your body needs to eat" (Bill, aged 10)

When asked about the personal value of science to them, the children's answers barely referred to their visual impairment. Their perceptions of its value was illustrated with examp les such as the need to know about electricity, gas and the aroma of decaying food as matters of personal protection and safety. Some also described the value of science in terms of the inherent value of knowledge. For example, one child told us that it is:

"...good to know about the world around you and how everything works...it is important.” (Ben aged 12)

And the eldest child told us:

"...generally you learn about the world around you, about planets... everything are the way they are because there are certain rules they follow... and some rules cannot change ...like gravity...we cannot change that ... otherwise we wouldn't be able to have balance." (Brian aged 13)

The youngest child, though, was the exception as he questioned whether it was necessary to need to know how plants grow as food can be purchased and neither could he see the necessity of understanding the climate cycle.

\subsection{Children's Enjoyment of doing Science}

A pilot study,[10], of children's perceptions of science education compared those at the end of their primary school education (i.e. at ages $10-11$ ) and those at the start of their secondary school education (i.e. at ages $11-12$ ). They found 
that a high proportion of both groups of children reported a high level of enjoy ment of doing science. The most common view of the two groups about the purpose of practical science classes is that they enabled them to develop their knowledge about science. A less common but equally held view of both groups is that the lessons are a fun and enjoyable way of learning. All the children in our study said that there was not any part of science that they did not like except, perhaps, for the eldest child who said that he did not like some parts of chemistry. They all identified aspects of physics as their favourite scientific subject. Two chose electricity, one light and shadow and one enjoyed to learn about cosmology and gravity. With such a mall sample, we cannot of course know whether their preference for physics is typical of vision impaired children.

When the children in our study were asked to describe their favourite science topic, one of them explained his choice in terms of being visually impaired. For example, learning about the positive and negative ends of a battery for that child meant that:

"My favourite is electricity ...for example I know how it works and because I can't see it is very useful... what I mean is If I need to put batteries in something I know where it will go, because I can't see but I can feel it...I use batteries in my brother's car, and we play together and the car works." (Ben aged 12)

But the eldest child saw his preferred interest in gravity in terms of the general value of knowledge and the beneficial value of this knowledge to all people, irrespective of whether they are visually impaired. Perhaps this was because the child was studying at a more advanced level than the other children. They also described the general importance of science with barely any mention of their visual impairment. Indeed, one child did not see this as especially relevant to the understanding of science:

"You don't really have to see things around you if you know how they are made of and how they are working" (Bob aged11)

\subsection{Vision Is Not Central to Understanding Science But Concepts And Processes Are}

And when asked to describe the aspects of science that they found the hardest, three of the children described things where vision was not central to understanding but concepts and processes were. The topics so described were the climate cycle of water evaporation and rain; the weights of solids, liquids and gases; and mathematical equations. The instance of where vision would otherwise be an important part of learning was the child who found it difficult to remember the diagrammed of the human heart. Consistent with the children's ability to understand phenomenon that had a strong visual component, were the experiments that two of the children spontaneously recalled when asked to describe and explain them. These were experiments to understand photosynthes is by growing seeds in light and dark conditions and to understand how using heat turns solids into liquids and then into gas.

\subsection{The Value of Pr ofessional Science}

When the children in our study were asked whether they wanted to become scientists, three of the children specifically referred to their vision as a reason for not becoming one or of being a significant issue, especially in the risks, challenges and dangers of a visually impaired person carrying out experiments. For example, one child said:

"I cannot see ... I mean it's going to be very difficult and maybe dangerous to do all these experiments ..." (Ben aged 12)

However, they also gave other reasons for their choice such as their preference for music or their difficulty with equations. The exception was the youngest child who said he wanted to become a scientist, although his motives were probably not ones that most would encourage!

"if they discover everything there is not much work left for me...so I will have lots offree time." (Bill, aged 10)

Reference[6], found that about a third of the children in both their age groups believed that those who do science as part of their jobs do so because they enjoy doing it and finding out about new things. A similar proportion of the younger group see that the purpose of science is discovery, such as finding new medicines, while half of the older group share this opinion. They a lso found that younger child ren can have an "interesting and perhaps unexpected" sophisticated understanding of science. They quote 10 to11 year old children that told them:

"People get paid for it and the people do stuff that is important."

"The practical science that people do in their jobs is a bit different because they know that they might make a difference to the world."

These researchers[6] expressed their surprise that the younger children held strong views about the value of professional science and that those who practice it enjoy it which makes them motivated to do it. The children in our study shared similar views. The children in our study were asked to describe the role of scientists and the strong common perception was that the job of scientists is about discovery by being able to understand new things such as how things work or by being able to predict natural phenomenon. And their perceptions of scientists reflected their recognition of the scientific method and of the task of discovery by describing scientists as "clever" and those who want to "discover things." In talking about discovery, one child saw the potential contribution that science could make to visual impairment:

"...who knows they might also discover something for blind people so that they will help them to see visual images." (Brian aged 13)

\subsection{Stereotypical Perceptions of Scientists}

Barman (1996) found that the mainstream school child ren that they interviewed had largely stereotypical perceptions of scientists as being white and male. Perhaps unsurprisingly 
the children in our study also had stereotypical views of scientists as wearing white robes, working in laboratories and universities and writing books. Some of their answers also had the innocent charm of children of this age. For example, Ben (aged 12) said that:

"I don't know if they have time to have fun and if they are happy because they must spend the most of their time in their laboratories ...but certainly they must be very clever otherwise they wouldn't make discoveries."

And Bob (aged 11) said that:

"...they are not like ordinary people, they are very clever.”

\section{Discussions}

Our study raises general questions about educational research methods with children in general. We saw how the focus on one issue in the early part of the interview led shaped their answers in a subsequent part of an interview. The structure of the interviews was designed to elicit children's views and we kept in mind the principle that the questions should be brief and simple and unfold like a normal conversation. Thus rather than asking strongly focused questions, which might inhibit the flow of the conversation; we asked questions that did not always follow the sequence laid down in the interview guide. The questions sometimes followed the sequence we deemed best based on the information that emerged during the interview; for example when the actual flow of the discussion led naturally towards a question that came later in the set order. That strategy provided the opportunity for topic areas to be revisited and enhanced the depth of the information obtained for analysis. In addition, although the children guided the conversation in relation to the specific questions, a set of standard value-free prompts (such as "What makes you think so?”, "Can you tell me more about that?", "go on” etc.) were developed for children who found difficulties in beginning or completing their answers. The significance of this is for research methods[8].

As far as concern children's views on science, many researchers ([2],[10], and[11]) found a strong association between children's enjoyment of practical science lessons, the social value they attach to science and positive attitudes to the subject. Our sample was too small to test this connection but our findings are consistent with it and it is a relationship worthy of future exploration. Children's enjoyment of science might reflect on the way these children are taught science. For example the choice of topics which might be relevant and interesting to them, understanding of science as a process of learning that has applications in everyday life, understanding that these applications might be beneficial but can also be damaging and so on[12].

A study,[11], of mainstream school children found that children largely see science as a lesson where they would be taught about how to use scientific skills, such as observation and measurement, in their everyday lives. Children in our study also suggested that it was necessary to have a good grasp of mathematics to be a scientist and gave examp les of the use of maths in counting, measuring and equations and mentioned the specific mathematical skills of addition, division and multiplication. Towards the end of the interview, the children were asked to give examples of measuring and estimation. Each of their answers was directly linked to their earlier examples of scientific activity. For example, the child who described the life cycle of plants described the need to measure water to carry out an experiment on the life cycle of plants and the child who described gravity as an examp le of science described the gravitational measurement of Newtons as a means of measuring weight. Two of the children also emphasized the methods of experimentation, observation and comparison.

A line of argument running through these four children's account about science is the largely marginal role that vision has to their understanding and perceptions of science. Vision is not central to their specific enjoyment of the subject although they referred to their blindness as a barrier for them to become scientists. They referred to the challenges that they might need to encounter. This may suggests that at a young age they readily accommodate their limited vision into a subjective appraisal of their future career choices. This raises a question about the extent to which adult career choices are constrained by visually impaired children's perceptions of their potential at a young age. In the context of this study, there may be positive examples to show vision impaired children of scientific activity where vision is not a necessary prerequisite. Perhaps the most distinguished mathematicians who is blind is Professor Abraham Nemeth, a former professor of mathematics at the University of Detroit. He conceived and developed the Nemeth Braille Code for Mathematics and Science Notation to enable blind children to learn mathematics. Perhaps examp les such as him and his method could be used to inspire vision impaired children about science as a career option.

That they did not see themselves as scientists in the future may also reflect the stereotype they had about scientist. Children in the present study perceive scientists as white males, wearing white robes, performing experiments and practicing science in a laboratory. Thus educators have responsibility to help students realize that scientists are everyday people and are represented by both genders and are fro m a variety of ethnic backg rounds[11].

Our primary purpose in reporting the findings from this small scale study was the hope that other researchers in the field will want to investigate our tentative findings in more depth. For example, such a study might help to refine the methods of teaching science to visually impaired children. For example, one of the children in our study said that he struggled with understanding the daigramme of the heart. This child was as would the others taught the structure of the heart and other diagrammatic representations using tactile diagrammes. The question then is the extent to which visually impaired children struggle with these diagrammes and whether the related teaching methods need to be refined. 
The conclusions from our study can only be indicative, however all the children seemed to enjoy science education enormously and their experiences challenge any myths that there might be about visually impaired children's enjoyment of things that might otherwise be seen as visual experience.

\section{REFERENCES}

[1] Y. Andreou, and K. Kotsis, "The Perception of Basic Science Concepts by Blind and Sighed Children” The International Journal of Learning, Common Ground, vol. 12, no. 1,pp. 253-258, 2006.

[2] I., Durre, "Success for blind students in mathematics and science: The importance of thinking outside the box." Paper presented at the Seventh International Conference on Higher Education and Disability, Innsbruck, Austria, July 2010.

[3] R., Osborne, and M.C. ,Wittrock, “Learning science: A generative process" Science Education, vol. 67, no. 4, pp. 489-508, 1983.

[4] R., Driver, “Adolescent Development and school science” In P., Adey (ed.): Changing con ceptions., Falmer Press, 1989.

[5] J., Solomon, “The rise and fall of constructivism” Studies in Science Education, vol. 23, pp. 1-19, 1994.
[6] J., Cumming J. "Why are misconceptions in science so hard to change?” 1991. Online Available: http://www.leeds.ac.uk/ed ucol/documents/000000932.htm Education-line database

[7] R., Osborne and P., Freyberg, "Learning in science. The implications of children's science”. Heinemann Education, 1992.

[8] Y., Andreou, "Investigating the spatial understanding of children who are blind through the use of the child's voice". Ph.D. thesis, University of Birmingham, 2011.

[9] Y., Andreou, and McCall, S. "Using the voice of the child who is blind as a tool for exploring spatial perception". The British Journal of Visual Impairment, vol. 28, no 2,pp. 113-129, 2010.

[10] M., Braund, and M., Driver "Moving to the big school: what do pupils think about science practical work pre- and posttransfer?” Paper presented at the Annual Conference of the British Educational Research Association, University of Exeter , England , 12-14 September 2002.

[11] C., Barman "How do students really view science and scientists? Science \& Children, vol. 34, no.1,pp. 30-33, 1996

[12] M., Littledyke, "Primary children's views on science and environmental issues: examples of environmental cognitive and moral development". Paper presented at theEuropean Conference on Educational Research, University of Lisbon, 11-14 September 2002. 